\title{
GUIDELINES FOR STRATEGIC PLANNING
}

\section{DO NOT MICROFILM COVER}

\section{Department of Energy}

Office of Policy, Planning and Analysis

July 1991 


\section{DISCLAIMER}

This report was prepared as an account of work sponsored by an agency of the United States Government. Neither the United States Government nor any agency Thereof, nor any of their employees, makes any warranty, express or implied, or assumes any legal liability or responsibility for the accuracy, completeness, or usefulness of any information, apparatus, product, or process disclosed, or represents that its use would not infringe privately owned rights. Reference herein to any specific commercial product, process, or service by trade name, trademark, manufacturer, or otherwise does not necessarily constitute or imply its endorsement, recommendation, or favoring by the United States Government or any agency thereof. The views and opinions of authors expressed herein do not necessarily state or reflect those of the United States Government or any agency thereof. 


\section{DISCLAIMER}

Portions of this document may be illegible in electronic image products. Images are produced from the best available original document. 
This report has been reproduced directly from the best available copy.

Available to DOE and DOE contractors from the Office of Scientific and Technical Information, P.O. Box 62, Oak Ridge, TN 37831; prices available from (615) 576-8401, FTS $626-8401$.

Available to the public from the National Technical Information Service, U.S. Department of Commerce, 5285 Port Royal Rd., Springfield, VA 22161. 


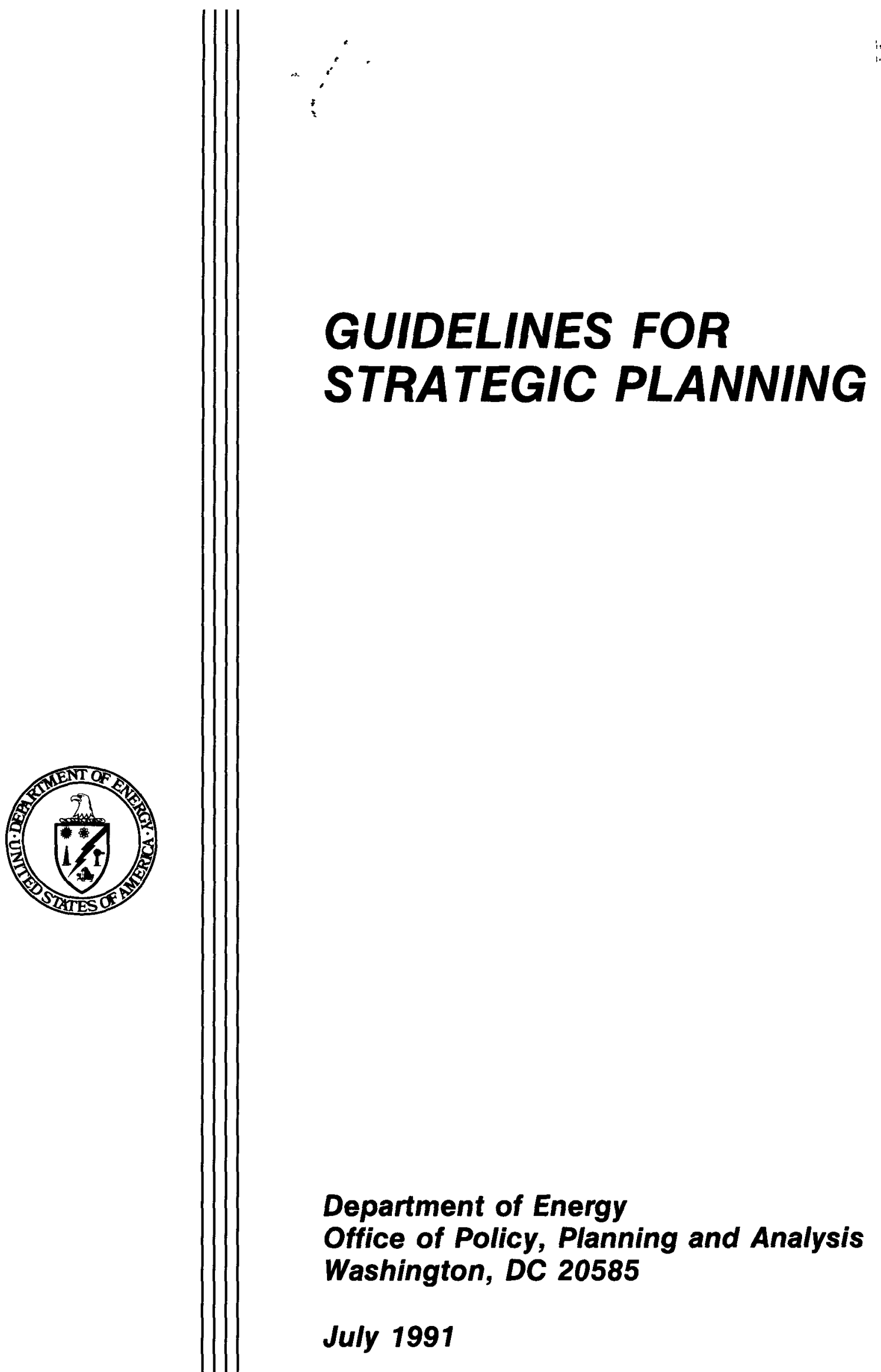

DOE/PE--0099

DE91 018129

\section{GUIDELINES FOR \\ STRATEGIC PLANNING}

Department of Energy

Office of Policy, Planning and Analysis Washington, DC 20585

July 1991 


\section{Table Of Contents}

Introduction and Overview ............................................................ 1

Planning for Strategic Planning ...................................................... 5

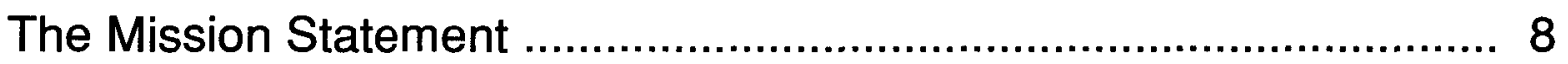

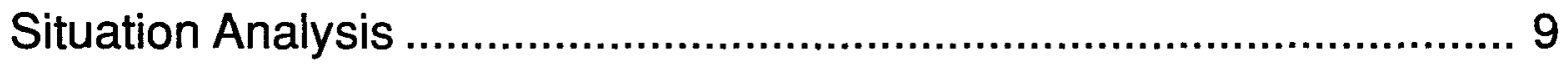

Vision and Strategic Goals and Objectives .....................................12

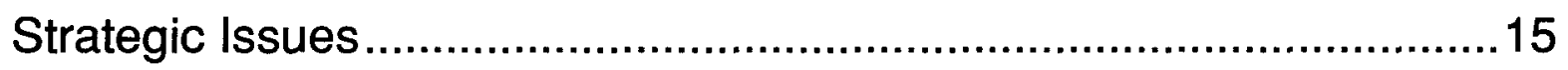

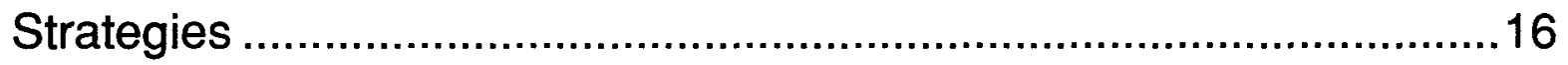

The Next Steps: Program Planning..................................................18

How To "Do" Strategic Planning .......................................................19

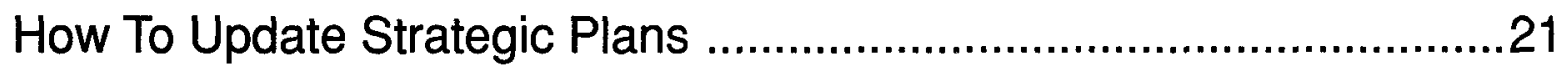

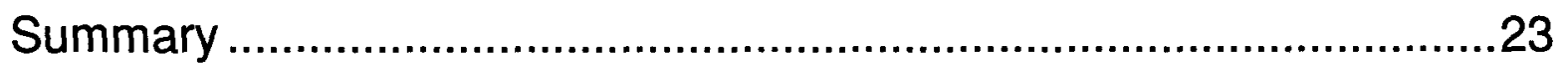

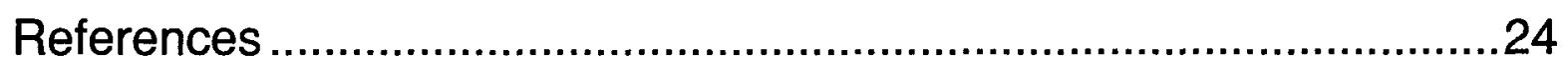

Appendix: Example of a Strategic Plan Summary .............................. 


\section{Introduction and Overview}

\section{THE NEED FOR STRATEGIC PLANNING.}

Strategic planning needs to be done as one of the integral steps in fulfilling our overall Departmental mission. The role of strategic planning is to assure that the longer term destinations, goals, and objectives which the programs and activities of the Department are striving towards are the best we can envision today so that our courses can then be set to move in those directions. Strategic planning will assist the Secretary, Deputy Secretary, and Under Secretary in setting the long-term directions and policies for the Department and in making final decisions on near-term priorities and resource allocations. It will assist program developers and implementors by providing the necessary guidance for multiyear program plans and budgets.

It is recognized that strategic planning has been carried out and effectively used in many of our programs and activities. All Program Secretarial Officers are required to develop and maintain current strategic plans for their organizations. They may choose to require subsidiary strategic plans from parts of their organization which make up logical planning units. Other Secretarial Officers are encouraged to develop and maintain strategic plans in their line and staff organizations to facilitate the kind of strategic thinking and management needed to ensure departmental activities are carried out in a manner most supportive to overall administration and departmental strategies, goals, and objectives.

The purpose of this document is to provide guidance to those organizations and personnel starting the process for the first time as well as for those who have prepared strategic plans in the past and now wish to review and update them. This guideline should not be construed as a rigid, restrictive or confining rulebook. Each organization is encouraged to develop such enhancements as they think may be useful in their planning. The steps outlined in this document represent a very simplified approach to strategic planning. This simplicity will allow for flexibility of use in many different kinds of DOE activities and yet will generate those minimum elements necessary to achieve basic uniformity of approach which will facilitate review by DOE Principals and use by appropriate line, staff and field organizations. For those wishing a more detailed approach to strategic planning than that contained in this guideline, you are referred to John Bryson's book "Strategic Planning for Public and Non-profit Organizations" listed in the Resource Table at the back of this document on page 24.

\section{WHAT STRATEGIC PLANNING IS.}

The operational planning most of us are so familiar with deals with how to get things done and with the resources needed (people, money, facilities, time) to carry out tasks. Operating plans like budgets, capital line item projects, $R$ \& $D$ budgets, project proposals, etc., are vital to the mission of the Department. They deal, however, with how to carry out programs to achieve some objective or budget assumption. Strategic planning deals with the prior question of what it is that should be attempted. It deals with what objectives the many programs and activities of the Department should be striving toward. Note that this is a basic and qualitative difference. It is not just a matter of the planning horizon being much longer. Adding 1020 years to an $R$ \& $D$ budget, for example, may make it a long-range plan but not a strategic plan. One distinction between strategic planning and the usual long-range plan is that of breadth. Long range plans often are largely an extrapolation of the present mission, issues, opportunities, etc. into a predictable future rather similar to the present. Strategic planning will assume turbulence and changes, will ponder future alterations in missions, markets, and customers; will consider a variety of trends which may impact us, opportunities and threats both external to the organization and internal; and possible new future issues and alternative strategies to resolve them. Also, while strategic plans will spell out where we hope to be sometime in the future, they do not lay out a detailed road map to get there. They offer strategies- 
basic directions or courses of action-but not operating plans.

Another notable difference is that the operational plans we deal with are usually "bottom-up" plans, generated by the field or staff in accordance with assumptions they have been given and objectives to be reached. In strategic planning, which deals with the generating of the "right" objectives, we need to also use a "topdown" approach. The best thinking of the Secretarial Officers and their organizations about the future they would envision for the Department and the Nation is required. The question to ask is: What do you envision the "world" you're working in would be like in the longer term future if the programs or activities you are responsible for were to be really successful? Again, what is wanted is the best thinking about the future we should strive toward-not reams of paper, not carefully crafted forecasts of what the future may be, not extrapolations of the status quo, and not the products of special staff consultants or of outside contractors. The output of the strategic planning work should be a thoughtful digest of your organization's thinking and discussions, summarized in as few pages as possible ( 8 or less, see below).

\section{THE KEY ELEMENTS IN DOE STRATEGIC PLANIING.}

Strategic planning is not a science. At its best it is a process for helping people think about the objectives they should set if they are to fulfill their mission and then what directions they should move in to go about achieving those objectives. There are about as many strategic planning processes and approaches as there are strategic planners! But there are some common denominators and, although each organization is free to adopt different processes as seem most expedient or appropriate to their organizational component, the following six elements must be developed as a minimum:

\section{Mission}

(Businesses, task, or purpose)

There may be several in a given organization. Why do we do what for whom and how?

\section{Situation Analysis}

(Environmental Scanning)

Where are we today in terms of our mission? What's "our world" like and our likely future?

Who are our customers?

What are our planning assumptions?

What are our strengths and weaknesses?

\section{Vision \& Strategic Objectives}

What do we hope to achieve and how will we know if we get there? What are the key performance indicators for us?

\section{Strategic Issues}

(Gaps between situation \& vision, obstacles)

What obstacles or barriers do we see?

\section{Strategles}

(Courses of action to overcome barriers and accomplish objectives)

What directions or courses of action should we set out on?

\section{Program Planning}

(Plans which translate strategies into actions)

These steps are mentioned above by way of introduction. Each is described in more detail in the Chapters which follow.
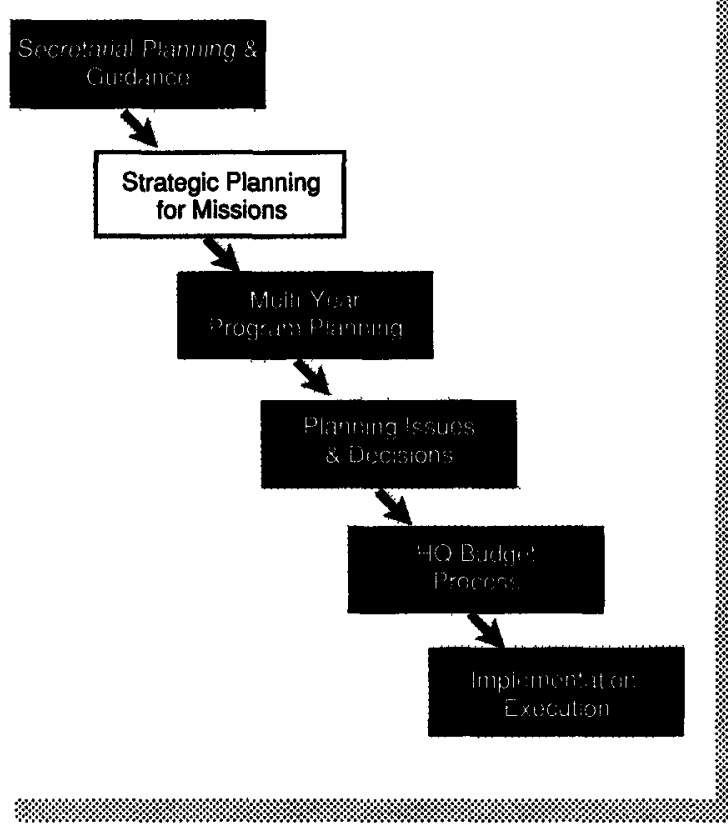


\section{THE "TIE-IN" TO THE DOE PLANNING AND BUDGETING PROCESS.}

Strategic planning is one of the essential steps in the Strategic Planning Initiative originally called for by the Secretary in SEN-11-89 and in SEN-25-90 as updated by subsequent policy and Departmental directives. By generating a clear statement of mission, long-term objectives and directions (strategies), strategic planning can provide an essential basis for multi-year program planning so necessary for the day-to-day management of program activities.

The publication of the National Energy Strategy (NES) now constitutes part of the guidance for strategic planning and should be supported and implemented in program strategic and operational planning. An overview of some of the steps in the DOE planning and budgeting architecture is shown in the above chart.

\section{LESSONS LEARMED ELSEWHERE ABOUT ACHIEVING SUCGESS II STRATEGIC PLANIIIIG EFFORTS.}

Experience with a number of different approaches to strategic planning within DOE, its contractors, and other institutions suggests some important "lessons learned:"

\section{a. The same people who are account- able for getting the job done must do} the strategic planning. Information gathering, analysis, and other parts may be delegated to staff specialists or to subordinate managers, but defining the mission, objective setting, and strategy development should be a participative process involving the key "line" managers led by the Secretarial Officer or by the appropriate line manager in charge of the function being planned for. It is almost impossible for a task force or team to transfer the sense of conviction or excitement they developed in days of agonizing through a planning process to a "higher" level group of managers. Any plan developed by people other than by those directly responsible for "running" the part of the enterprise in question is almost certain just to be filed away along with all the others done by "special groups"-regardless of how competently they have been done or how good the planning group is.

b. The key managers involved must recognize this is an important part of their job duties, and they must be willing to commit the time, energy, and resources required for the work. It is crucial that the time required to do this thinking be set aside and protected for the sake of all concerned. When the scheduled dates for strategic planning meetings approach, there is always the realization that this week's crises are much more pressing than 10 to 30 year thinking!

c. The one thing certain about the future is that it will be different from what we expect it will be today. No matter how seriously or elegantly we plan for 2000 or 2030 , in just a few years the threats and issues will change dramatically, just as they have in the past few years. Accordingly:

- Don't spend too much time or detailed effort in forecasting elaborate scenarios of the distant future.

- Revisit your strategic plan of record at least annually and update it to reflect the changing world.

- Bring "on-board" and take advantage, of the new insights and contributions of any new members of the management team.

d. If there is not a tight link-up with the rest of the program planning and budgeting process, with a constant infusion of strategic thinking into ongoing operating decisions, management actions will usually evolve into, or simply remain in a largely reactive, crisis-driven, status-quo mode.

e. One key to real success in strategic planning is the willingness and ability of the key line manager for the group (Secretarial Officer) and his/her "direct 
reports" to think beyond today's crises, priorities, and incumbent's desires (self, peers, bosses, and others) and to search for what is the "right" thing to do in the longer term best interests of the enterprise (in our case, the Nation). The trap into which many people fall is to start thinking about where they are today and then extrapolate to (1) what they think it is possible to achieve or (2) what they think will most please some important stakeholder. The courageous and muchneeded approach is one where the top DOE officials (using the best inputs available to them) try to envision what would be the best for their part of the organization to try to accomplish for the longer term future best interests of our nation.

\section{f. Most people feel afterward that the} strategic planning process is more valuable than the product. It is the debating, sharing of convictions and doubts, and pondering that is most valued. Later, when change occurs and must be reckoned with, that particular management team will have a strong basis on which to build and agree, having already discussed and reached accord on many of the issues.
George Washington, just before the beginning of the Constitutional Convention in 1787, hearing whispers from his fellow deputies of the need for caution and for being careful not to propose too bold or innovative ideas which might rouse opposition, spoke out against the idea of offering half measures that were sure to succeed, rather than to risk whole measures that might fail and discredit the delegates.

"It is too probable that no plan we propose will be adopted. . If to please the people, we offer what we ourselves disapprove, how can we afterwards defend our work? Let us raise a standard to which the wise and honest can repair ..."

- Carl Van Doren, Ihe Great Behearsal, Penguin 1986,p.15. 


\section{Planning for Strategic Planning}

\section{WHO SHOULD DO THE STRATEGIC PLANIIIG?}

Back in the 1960s, staff strategic planning groups were in vogue throughout U.S. industry, but is was found that unless the people who are actually responsible for carrying out the programs do the strategic planning, it is very sure to be a futile exercise. Setting strategic objectives and developing the key strategies to achieve the missions of the programs and other activities of the Department is a task the Secretarial Officers must be personally involved in. There are many areas in which support and help by their staff specialists will be most useful (for example, data collection, trend analysis, documentation, etc.), but delegating the key tasks of envisioning and of debating objectives and strategies to staff specialists will not work. This guideline document is written for and intended for use by the Secretarial Officers as they plan for, organize, and prepare their strategic plans.

On the other hand, the Secretarial Officers and their "direct reports" should not try to do the strategic planning job in a vacuum. Especially with programs that are complex technically or managerially, field experts may have thought deeply about longer term objectives, obstacles and possible strategies and their inputs should be sought, even in some instances as planning team members.

\section{SINGLE PLAN OR MULTIPLE PLANS.}

Some Secretarial Officers will feel that their responsibilities can be best planned for as separate missions or "businesses," each with its own strategic plan: mission statement, situation analysis, etc. For example, the Assistant Secretary for Nuclear Energy may decide that the naval reactors and uranium enrichment activities are best planned for separately and choose to treat them as independent strategic planning units. Developing separate plans will help clarify and sharpen the focus of the Secretarial Officer's overall strategic plan and will be beneficial in the subsequent program planning activities - but will, of course, require more time and effort. If the mission statement that all Secretarial Officers prepare for their overall areas of responsibility is carefully written (see below), it will suggest the appropriate subdivisions that should at least be considered for treatment as strategic planning units, each having separate strategic plans. Because of the effort entailed, the question of how many planning units should be chosen is of major importance "up front" in the process. Because of the wide variety of programs and activities in the Department, flexibility is provided for so Secretarial Officers can make the packaging choice that will most benefit their organizations.

\section{PLANIIING PERIOD OR HORIZON.}

Flexibility is also provided for Secretarial Officers to determine the most appropriate time frame to cover with the strategic planning for their organizations. Probably the minimum that should be considered is for the next ten-year period. At the other extreme might be a fortyyear horizon for programs or activities that require or would justify it. (As will be seen later, this is a horizon for envisioning the future, and the task will not be to lay out a plan for how to get there-only how to get moving toward it). In his Notice of September 5, 1989 (SEN-11-89), the Secretary said: "The President, the Congress, and the American public should be able to see where we are going and why-near term, mid-term, and for the long haul." The decision on planning horizon defines what this long haul is for each organization.

\section{TIME AND EFFORT REQUIRED.}

Wrestling with the long-term objectives and future of a vital part of the DOE business is going to take some extra time and effort. We are very practiced in handling crises and this year's priorities. Thinking strategically is something with which many of us have less experience. A recent text on strategic planning urges managers to be realistic about the effort required and cites specifics about the author's experience:

"An organization should expect to spend between 10 and 20 full days of meetings to 
complete the (strategic) planning cycle ...one worked with 12 days ... another reduced this to 9 days by assigning extensive between-session work to internal staff consultants ..."

Pfeiffer et al. Shaping Strategic Planning, page 88. (Ref. 7)

In the case of a relatively uncomplicated program or activity, our estimate is that the minimum time might be reduced a little more, to perhaps six to eight days for writing the first plan. This estimate assumes not doing more than called for to meet these minimal guidelines and assumes maximum use of staff and a facilitator to expedite the process. Many organizations (including DOE components) have spent much more time than this in developing their strategic plans. Review and update can be done in half that time if the planning team membership is not much changed.

The time required to write or to update a Strategic Plan is also dependent on the number of people on the planning team. The Secretarial Officer will chair the team, ideally constituted of 5 to 7 "direct reports". The accountable line managers should be included, as described earlier. Increasing the number to 10 to 15 requires longer meetings to ensure participation by all, but often the benefit of more participation justifies the added cost.

Since the process of strategic planning will very likely run over a period of months (just for one year's cycle), another problem encountered is that of personnel turnover. This is another factor which may require extra time, because it is very important (especially in small teams) to quickly bring new people up to speed with the process.

\section{THE PROCESS}

It is almost impossible to do strategic planning as part of the normal business day, interrupted by today's crises, urgent phone calls, emergency meetings, etc. It is best done in offsite meetings, with well-planned, well-prepared, tight agendas that recognize the importance of participation by all of the key manager's involved.

Experience has shown also that the use of a competent facilitator to assist in designing and conducting strategic planning meetings can help considerably in keeping the sessions on track (there is a bias toward slipping back into discussions of today's issues). A competent facilitator can help the Secretarial Officer in leading the group to be more productive.

In later Chapters of this document specific suggestions are offered about (1) how to set up and plan meetings for developing strategic plans and (2) how to update them. But the wide variety of programs and activities with greatly different needs for consideration of customers, trends, etc., means that a generic, simple, process model should not be mandated and that each Secretarial Officer will want to design a process appropriate to his/her own organization.

\section{WHAT SHOULD THE PRODUCT LOOK LIKE?}

Secretarial Officers and planning teams should document their strategic thinking in whatever length and detail they feel will best meet their needs for guiding the program planning that must follow in their $\mathrm{HQ}$ and Field organizations. Experience elsewhere has shown that piles of paper supporting strategic planning are of little or no value. Multi-year program planners will be primarily interested in the objectives, issues, and strategies together with some of the thinking (situation analysis and planning assumptions) that led to those choices.

For reviews with the Secretary, other DOE Principals and for use outside of the Department when necessary or desirable, an abstracted, very succinct summary version will be prepared. It is perfectly acceptable to present it in 3 to 5 pages if the heart of the planning can be condensed that much. The abstracted version for Secretarial review of new or updated plans will in any case be no more than 8 pages.

The content of the summary 8 page version will include the key outputs of the planning team's work: the mission statement, key situation 
analysis factors (trend analyses, planning assumptions, stakeholder considerations), key strategic objectives, key strategic issues, and key strategies. An example of a summary of the strategic plan for a wholly fictitious DOE program is included in the Appendix to give an idea of what the abstract for the Secretary might look like.

\section{REVIEWING AND UPDATING STRATEGIC PLANS}

Strategic plans should not be thought of as final statements or immutable creations, but rather as the best ideas or today's leadership team in view of today's realities. The one thing that is certain about any strategic plan is that it will be wrong in its details! The future will be different than it is pictured today. There will be new technologies, new laws, new threats, new opportunities, new crises, etc. It is essential that change is anticipated and allowed for.

The strategic plans must be reviewed at least annually by the Secretarial Officer and the planning team. Whether plans should be reviewed more often is up to the Secretarial Officer and should be a function of how fast and how extensively change is occurring and impacting their program. For instance, any changes in mission, mandates, or key personnel may trigger the need for a complete revision, and if those changes are major ones, a completely new plan should be written and approved by DOE Principals. For most changes in a program's environment, the needed revision or updating can be accommodated in an annual review process such as described in the later chapter on that subject. The "ownership" of the plan needs to remain with the planning team, so it is suggested that the temptation be avoided of letting any individuals "adjust" or "fix" parts of the plan to correct specific problems in between reviews.

In the annual review, the Secretarial Officer and the planning team, some of whom will be new to the group, need to revisit all the elements of the plan. The major input to the review should be briefings by staff specialists on various aspects of the situation analysis, especially: changes in market demands, competition, stakeholder expectations, laws, economy, technology, other trends, etc.

The planning team will then need to do their own self-assessment of the situation (strengths, weaknesses, opportunities, threats, planning assumptions, progress on key performance indicators). With this work, in combination with the staff briefings, the team can very effectively update their objectives and strategies. Assuming good preparation, the review and updating should be efficiently done in one annual offsite.

The output of the annual review and update will be a revised plan in whatever form the Secretarial Officer desires. As stated earlier, if the plan is longer than 8 pages, an abstracted version for use during reviews by DOE Principals is required. The Secretary will want to review any substantive changes in direction or situation that comes out of the annual review. Significant changes outside of the normal review cycle should be brought to the attention of the Deputy or Under Secretaries for their approval. Minor changes in the plans outside the normal review cycle should be made by the Secretarial Officer and planning team. 


\section{The Mission Statement}

Every organization exists to serve a purpose. Each component part of that organization also exists to carry out some task or mission of its own. Agreeing on just what this unique mission or purpose is provides the essential foundation for strategic planning.

Because most line managers rarely have a need to discuss it, the mission-or basic purpose of their organization-is often taken for granted and not scrutinized. Discussing it and getting agreement by the planning team on as clear a statement of what the job(s) is/are can be very desirable. Far from being obvious, clear statements are often hard to develop, and choice of goals/objectives is usually sensitively dependent on concept of mission.

Mission statements (like organizations) tend to stand for long periods of time. But they should be examined and debated periodically both by those to whom the organization "reports" and by those accountable for carrying them out. A whole hierarchy of missions exists in a large organization, and each level derives from the mission of the parent. It is obviously important for the planning team to be certain they are "working" the right mission.

The mission statement serves to clarify the purpose of the organization for people both within and outside. In addition to clarifying job(s), it should serve to narrow and focus, as well as to inspire and motivate. It should be debated and boiled down to the essence-100 words is one "rule of thumb" - which tells why we do what, for whom, and how in an easily understandable way. It should tell what products or services are provided to what customers (products) or clients (services) or sponsors, and it should tell what activities or kind of work we do to provide these products or services.

\section{MISSION STATEMENT - HELP MENU}

- Will it be clear to everyone within and outside the organization ?

- Does it tell what our job is, what needs we are trying to fill, for whom, how?

- Is it clear who we regard as our customers-not only who they are but who they should be?

- Is our primary focus or strategic thrust clear?

- Does it reflect our distinctive competence?

- Does it reflect our values, philosophy and beliefs?

- Will it energize, motivate, stimulate our organization?

- Is it brief enough for people to remember the main points?

\section{MORE HELP}

Reference 6, Chapter 5, pp 93 to 116;

Reference 8, Chapter 8, pp 117 to 133;

Reference 3, pp 107 to 10 


\section{Situation Analysis}

\section{PURPOSE}

The steps already covered will ensure that the following work has been accomplished:

a. Writing and debating the mission statement (purpose).

b. Deciding whether it is desirable to break down the broad mission for this particular segment into two or perhaps more separate units and preparing a mission statement and plan for each.

c. Deciding on the general planning time horizon that is appropriate.

The next appropriate step is to see where we are today in regard to that mission. The situation analysis (some call it environmental scan) is done by gathering facts and analyzing trends that give an objective picture of where we stand in the "world" of this business and the external and internal pressures and factors likely to affect our future. Staff specialists and key subordinate managers can be asked to do a lot of this work of gathering and analyzing information. For major corporations, the analysis of the business climate, market place, competition, etc., can get very detailed and voluminous. And for the major programs and activities of the Department the data collection could likewise easily exceed the capacity of the planning team to digest and assess it. The team will want to focus on information which may impact the choice of longer term objectives, particularly looking at the organization's stakeholders, key performance indicators, and trends that represent opportunities or threats, internal weaknesses/strengths, and planning assumptions.

\section{STAKEHOLDERNEEDS/WANTS/ EXPECTATIONS - WHO ARE OUR CUSTOMERS?}

Stakeholders is a common term in strategic planning and refers to those people who have or feel (perceive) they have a stake in the future success of the business or unit in question. We need to have a pretty clear idea of who these people are and of what their needs and expectations are as we develop the longer term strategic objectives of our business. Stakeholders obviously include management and employees (internal) and executive, legislative, regulatory groups, public representatives, etc. (external). One exercise that is often useful is that of drawing and discussing a stakeholder model of the business. This simply diagrams the business with its annual inputs and outputs (not quantified). The critical question is "Who Are Our Customers and Who Should They Be for this Planning Period?" This diagram may help the team think through what products are produced for what customers, what services for what clients, what information for what sponsors, as well as who are the external and internal stakeholders. Their points of view and expectations should all be considered in developing our strategic objectives.

An example of a stakeholder model is shown in the box below. It is the process of developing and debating that is the main value, not the actual graphic that results:

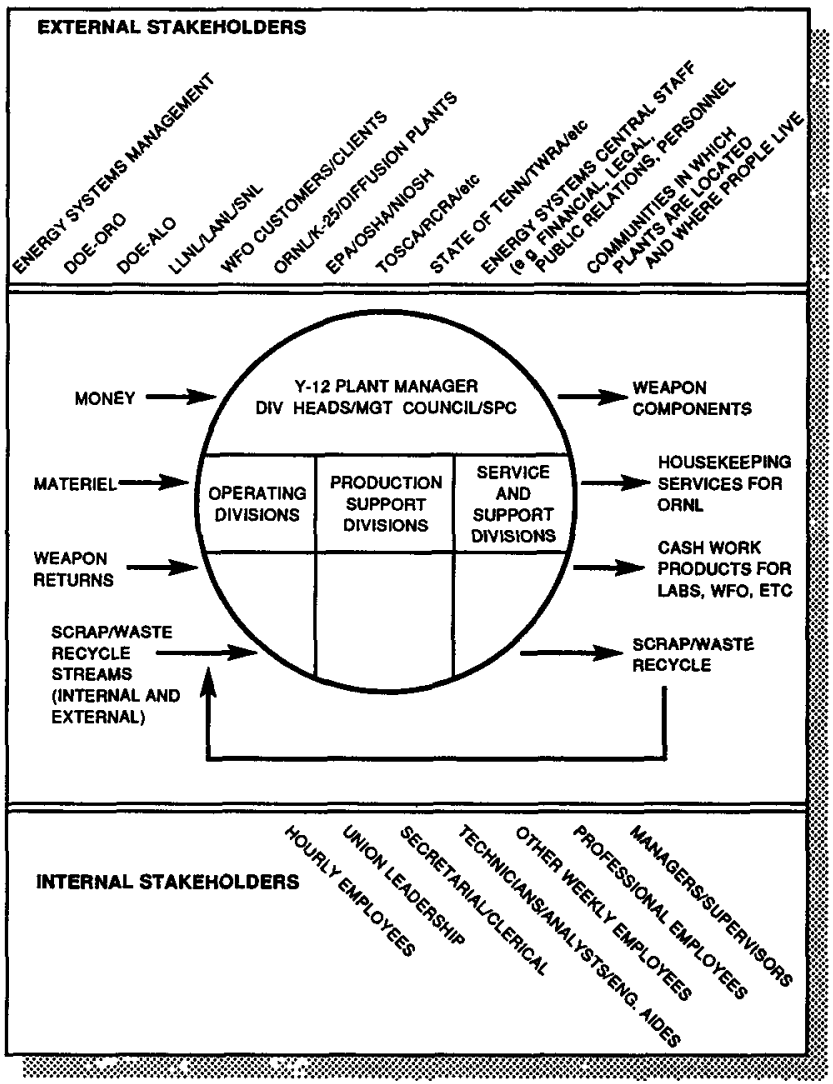


The discussions of who these groups are and what impacts they should or should not have on the strategic planning being developed should be useful. In past work, interviewing samples of various stakeholder groups in a threat-free environment has proved of much interest and some value. The Interim Report of the NES was a compilation of comments from the public and other stakeholder groups and is an example of the usefulness of listening to stakeholders.

\section{EXTERNAL STAKEHOLDERS (EXAMPLES)}

$\begin{array}{ll}\text { White House \& Staff } & \begin{array}{l}\text { Communities where our } \\ \text { Congress \& Staff }\end{array} \\ \text { Facilities are located } \\ \text { EPA } & \text { Scientific/Technical } \\ \text { OSHA } & \text { Community } \\ \text { NRC } & \text { Private Sector } \\ \text { NASA } & \text { General Public } \\ \text { Dept. of Defense } & \text { Suppliers } \\ \text { State Governments } & \text { etc. } \\ \text { Office of Mgt. \& Budget } & \end{array}$

\section{INTERNAL STAKEHOLDERS (EXAMPLES)}

$\begin{array}{ll}\text { DOE Top Management } & \text { Field Offices } \\ \text { Employees- } & \text { National Labs } \\ \text { Clerical, Professional } & \text { etc. } \\ \text { Contractors- } & \\ \text { service, M\&O, etc. } & \end{array}$

\section{TRENDS}

A valuable part of the strategic planning process is discussion and debate of the various trends that the group feels may impact the "enterprise" during the planning period. The important "trick" is to identify the key factors in the success of your segment of DOE activity and to see how those have been impacting the program in the past as well as projecting what's likely to be the future direction. Examples of the kinds of trends that may be felt likely to impact activities are:

\section{TRENDS}

Market Needs

Sociological Trends

Legal/Regulatory

Trends

Political Trends

Economic Trends

Institutional Trends

Technology Trends

Facilities Trends

Staff Trends
IMPLICATIONS

What will be our share? Increases/Decreases in Needs/Demands, etc.

Demographics, fmpacts on Sites, Environment etc.

Federal, State, Local. Changes/Outlook

Public Acceptance, Arms Control, Congressional Pressures, etc.

Budgets, Productivity

Pressures, etc.

DOE Organization

Structures, Changing

Roles

Improvements, Obsolescence, Break throughs

Aging, Fragility, Modernization (for What?) , etc.

Aging, Replacement of Expertise, etc.

These are only illustrative. For each organization, the question is what trends are most appropriate for analysis and success of the activity. The National Energy Strategy Interim Report had many excellent examples of trend analysis with both historical and future projections. Secretarial Officers will want their staffs to collect and analyze data for many of the trends listed above. Some will not be necessary (trends which will not impact your "business") and in still other cases, trends other than those listed above need to be addressed. The output of this trends exercise should be the recognition by the planning group as to which of these trends pose either opportunities or threats that should be responded to in developing goals and strategies later on in the process. Either threats or opportunities may well present a strategic issue: "How can we respond to given this situation...?" 


\section{STRENGTHS/ WEAKNESSES (OR ASSETS/CONSTRAINTS).}

Another important exercise for helping to identify goals/objectives is to do a performance self-assessment, looking very broadly at the program or activity in question. What we are really good at in this particular area, and which areas or activities we wish we could do better? Like the trends study above, weaknesses identified may be real obstacles to achieving our strategic goals and may be appropriately listed as strategic issues.

This is a useful way to flush those out which are of most importance.

\section{BENCHMARKS.}

Of course in business or corporate strategic planning, the matter of sizing up one's competitors is of critical importance. In most of our energy and other programs, we need to "compete" with ourselves, that is with our past best performance, striving over the long haul to carry out each of our missions ever more efficiently and more effectively. Continual performance improvement must be based on honest appraisal of strengths and weaknesses together with participation of all our people.

In those few areas of DOE programs where a true competitive situation does exist (e.g. UE), the situation analysis will include a careful analysis of the competition and later the developing of appropriate goals, issues, strategies, and action plans. In some DOE areas, competition has been minimized by the way missions have been defined (Lead Labs, Nuclear Weapons Complex production assignments, etc.) and in still other areas there is no other public sector or private sector entity doing such work. For those areas where true competition does not exist, organizations should compete with their past or with the very best entities in the same field, so called "benchmarks". Using "the best" in the world or Nation as a reference point for our Situation Analysis may be a useful way to ensure performance standards are as high as you desire.

\section{PLANNING ASSUMPTIONS.}

Throughout the course of looking at all the aspects of Situation Analysis the team should be alert to the implicit assumptions they are making or to those they choose deliberately to make as they think about the longer term future of their activity. Assumptions may be inherent in stakeholder needs/wants, customer/client projections, trends of market needs etc., and so on. It is important that the team be explicit about these planning assumptions so they can be presented up front in the written strategic plan. If the broad based assumptions (not boiler plate, but assumptions that impact objectives) that are being made are clearly and well enough set forth, these can then serve as a useful checkpoint for review of the plan to see if updates are needed as well as serving as a point of departure for review of objectives and strategies.

\section{SITUATION ANALYSIS - HELP MENU}

- Stakeholders. Who cares about our success over planning period?

$$
\begin{aligned}
\text { External }= & \text { "Bosses", Regulators, } \\
& \text { Various Publics, Customers } \\
\text { Internal }= & \text { "Bosses", Auditors, } \\
& \text { Employees, Contractors }
\end{aligned}
$$

- Future Trends.

Will they impact us/How? Opportunities and threats
Economic Technology

- Market Needs.

Will demands increase/decrease? What will competitors do? Threats?

- Past \& Present Performance.

- Strengths/Weaknesses.

For more help see Reference 6, Chapter 6: pp. 117 to 138 ; or Reference 8, pp. 135 to 58 . 


\section{Vision and Strategic Goals/Objectives}

\section{DEVELOPING STRATEGIC GOALS AND OBJECTIVES.}

These are the ends to which we will strive, or what we hope to accomplish in the long run (before the end of the planning period). It is helpful to make distinctions between differing kinds of ends: ideals (never reached), objectives (reached in the planning period), and goals (might not be reached in the planning period). Differing usage of these definitions-for goals and objectives - may be encountered. But the convention for DOE HQ will be to use the term "goals" to describe the broad ends and "objectives" to describe ends we will try to achieve during our planning period. In the context of long (10 to $40 \mathrm{yr}$.) planning periods we will most often talk about strategic objectives. Lyndall Urwick, one of the pioneer management specialists of the World War II era, wrote in 1941:

"The first characteristic of a good plan is that it is based on a clearly defined objective."

Whether the objectives are motivational and creative will depend much on the spirit of the planning team as they consider the present situation, the stakeholder's expectations, the various trends (threats/opportunities), and the assets and liabilities (past performance).

\section{ENVISIONING THE FUTURE.}

It may be very useful, either before or after listening to the situation analysis, for the planning team to consider their vision of what they hope the future situation would be like at the end of the planning period they have chosen. A question to raise is, "What would the DOE XYZ organization's situation be-what would you see in place-in 2020 if we really were successful in our programs?" This should lead to useful discussions of differing visions of the future. And then this should lead to agreements on some of the objectives we want to strive toward. As a fictional example, the DP team might ask, "What would the weapons complex configuration look like in 2025 if we really were successful between now and then?" This approach, using a leap forward to thinking about what success is really desired, facilitates discussions of the what questions and helps stave off the hows. From vision discussions, the group will then be able to generate a number of objectives, i.e. ends that we really desire (if the vision is to be realized).

Regarding the number of objectives, experience suggests that most planning teams have no trouble generating a large number (too many) objectives when the strategic planning is for a major site or program. There will typically be several objectives dealing with the program itself or with production or operations, as well as objectives dealing with people (employees), environmental concerns, waste management, health and safety, security, productivity and costs, quality, management excellence/systems, community concerns, and the like. Considering which are "musts" and which are "wants" and which of the latter are most important can be useful in narrowing the list to the key or essential strategic objectives.

\section{WRITIR AND EVALUATING GOAL/OBJEBTIVE STATEMENTS.}

For strategic objectives to be of most value, they need to be easily understood, they need to suggest ways of measuring their achievement or non-achievement, and they need to have a good balance between challenge and achievability. Achievement will be measured by key performance indicators appropriate to the activity involved. The objective should include a date if it is to be achieved before the end of the planning period. Credibility and inspiration will follow if the objective appears to be not too ambitious, but significantly advanced beyond today's status quo.

Questions the Secretarial Officer and team will want to ask about their proposed objectives are:
1. Do they suggest some means for measuring their accomplishment? What are the performance indicators going to be? (Percentage of energy demand supplied by nuclear, projected unit cost of power, etc.) 
2. Does the objective include a date by which it is to be achieved, if that date is earlier than the end of the planning period?

3. Will the objective as stated be useful in "driving" or guiding the preparation of the multi-year and other program plans?

\section{Are they challenging and bold enough:}

a. To show people we want something other than just the status quo?

b. To be stimulating, and to bring out even better efforts from our DOE team, revealing of our directions and some dreams for a better tomorrow?

5. Do they appear achievable, i.e. realistic enough to have people be convinced we're serious, not just dreaming?

Conservative managers will try to set targets they are pretty sure they can meet. Risk takers will try to set targets that will be attractive to those allocating the resources or that appeal to the most outspoken stakeholders. A balance is needed. If the probability of succeeding in reaching the objective is too low $(10 \%-20 \%)$, it may be exciting and challenging but people won't believe it's possible and will likely not be motivated long. Just the same, too safe an objective $(80-90 \%)$ will not be very motivating either.

Strategic objectives are intended to inspire and motivate the organization to reach farther than they think they will be able to grasp. It is quite acceptable for their probability of success to be 0.5 , whereas objectives in an operational plan must have a much higher certainty of being reached. Someone quipped: "There are no such things as unreasonable objectives, there are only unreasonable time frames!"

Another question that should be asked about the goal statement is whether the purpose or reason is self-evident. Sometimes it is useful to add an explanatory phrase "in order to..."

\section{PERFORMANGE INDICATORS}

As stated earlier, one essential feature of a well written objective is measurability. One author said "Goals are just dreams with milestones." The planning team after narrowing down their list of strategic objectives should address the question of how progress toward them can be tracked. It is more a matter of whether we are on the right track than a matter of accountability (as it is with operating plan objectives). If progress is not up to expectations, the planning team should seek the root cause and reconsider their strategies.

In most strategic plans there will be two or three key performance indicators (or critical success factors) which can be quantified and used to assess the success of the directions established. See, for example, the fictional list of three on page A-6. With strategic objectives reaching out a decade or more, the shape of the build-up or growth curve will have to be chosen pretty arbitrarily and little value will come from close numerical tracking. Nevertheless, watching the performance indicators on all objectives should be very helpful to the team's assessment of the strategies chosen.

\section{EXAMPLES OF STRATEOIC OBJECTIVES.}

Some hypothetical examples are given below, together with comments to highlight features.

- Provide a cost effective research and development program ready for decisions to be made with regard to deployment by the year 2020.

Comments: the year is critical to this objective statement, hopefully 50:50 chance it can be done by then. Decision point for deployment is clear? Realistic? Challenging?

- By 2020, have a nuclear power reactor design that has been demonstrated and ready for commercial use, that is economical (considering all costs including environmental) and that by using passive safety features eliminates possible repetition of accidents like those at Three Mile Island or Chernobyl. 
Comments: An example of adding on an explanation as to why an objective is desirable.

- Develop cost-effective solar technologies to provide $25 \%$ of the energy requirements of building in the near term and $\mathbf{5 0} \%$ In the long term.

Comments: This is an example of an objective that is maybe too "fuzzy". What do near- and long-term mean?

- Ensure that every student studies mathematics and science every year in grades $K$ through 12 as part of a core curriculum, so that knowledge by U.S. students of these subjects will be the best in the world by the year 2000 .

Comments: This is measurable and the performance indicators are clear, but how realistic/achievable an objective is it?
- Raise the level of scientific literacy, including knowledge of energy issues, in the adult public.

Comments: This is an example of an "ideal," not an "objective." We will still be striving toward this in the year 2040. One approach to sharpening it into an objective would be to add on "increasing the level to that of the average 1990 high school graduate by the year 2020" (assuming that the level of current high school students can be measured). research.

- Maintain U.S. prominence in basic

Comments: This also is an example of an ideal, not an objective. Note how difficult it is to evaluate without the Situation Analysis facts. One does not know if it is sufficiently challenging or if it is achievable.

\section{EVALUATIMG AN OBJECTIVE - HELP MENU}

- Is it measurable? What are the key performance indicators? How can we build an information system to track our progress?

- Is it challenging and bold? Will it excite and motivate?

Not just the same old stuff?

- Is it achievable?

Do we have at least a $50: 50$ chance of pulling it off?

- If it is to be reached before the end of your planning horizon, is there a date in the objective?

- Will it be just as desirable an objective in 2030 or 2070 ? Probably an ideal, could it be sharpened?

- Will this objective as stated be useful in driving multi-year program planning?

- Is the reason behind the objective apparent? Would it help program planners if you added some more words?

For more help see Reference 7, pp. 23 to 28. 


\section{Strategic Issues}

\section{DEVELOPIIT STRATEGIC ISSUE STATEMENTS.}

If the objectives we have set to translate our vision into reality are as challenging as they should be, there will be major differences between the situation our activity "is in" today and what we want it "to be" (as shown by our objectives). Strategic planning tools of various kinds have been developed for analyzing and closing (bridging) this gap. Perhaps the simplest approach is to study the objectives in light of the situation analysis and then ask the question, "What are the key barriers or obstacles or problems that must be overcome in getting where we want to be?" These, boiled down to some critical few, are the strategic issues that must be addressed.

This is the first step we take toward answering the question of "How" do we reach our objectives. Most managers are very experienced if not proficient in problem solving and by instinct feel much more comfortable in dealing with "How" rather than in the "What" area of objective setting. Articulating the issues can be a useful step in problem solvingmaking sure the problem we are about to solve is clearly understood.

Again it is important to accent the word "strategic". One must anticipate the tendency people on the planning team may have to just make a list of this year's problems and of what they know the top management is most anxious about. The key is to get the team to think over their strategic objectives, and to identify the most important (not all) and most likely problems or issues in achieving them (science, technology, funding, time, facilities, people).

\section{EXAMPLES OF STRATEGIC ISSUES.}

Strategic issues take many forms. They are most useful when they clearly define a problem so that the planning team can easily move on to suggesting courses of action to solve the problem. Here are some hypothetical issue statements.

- The U.S. cannot function in an energy emergency without refineries capable of converting strategic petroleum reserves and other domestic oil into refined products.

- How can the DOE develop an understanding and acceptance by DOE and by the majority of the public of the real relative risks of alternative energies?

- Insufficient funding, lack of coordination, and emphasis on short-term goals of R\&D activities defer the development and commercialization of new technologies.

- Large increases in the price of electricity have occurred at some utilities when nuclear power plants start commercial operation. Consumer reaction to these increases has been strong, leading utilities to shy away from large capital projects, both nuclear and non nuclear.

- How can the DOE's "ABC" organization go about achieving the downsizing needed in the long haul (strategically) without wrecking the operations, $R \& D$, and environmental actions needed at its sites in the short haul?

- To what extent could innovative productivity programs reduce the funding pressures of remediation, safety, security, compliance, audit and other such critical activities.

\section{Strategic Issues - Help Menu}

-What are the key obstacles that may keep us from realizing our vision?

- Is it likely a strategic barrier? Not something that will be taken care of in the next year or two?

- Is it specific enough to suggest strategies for overcoming or resolving it?

- Is it just a restatement of the undesirable situation we're in today?

For more help see Reference 6, Chapter 7, pp. 139 to 162. 


\section{Strategies}

The discussion of issues will generate a lot of ideas for how to solve those problems. In developing strategies we finally get to the point of the whole process, that of coming up with the directions we want to move in today and tomorrow in order to reach our long term strategic objectives.

\section{WHAT ARE STRATEGIES?}

Strategies are courses of action that will lead in the direction we must move to reach an objective or to overcome some obstacle. We can, of course, set courses of action (strategies) without thinking in any depth about objectives. We do so often both personally and professionally. We buy something we want and then think of reasons to justify the purchase. Many of us have encountered orphan programs or projects whose objectives are not well-understood or accepted by all. With so much careful planning work having been done in past years on the major Department programs, none of these strategic planning steps will be virgin territory. And with objectives and goals as critical to our Nation's future well being as DOE's goals and objectives collectively are, careful strategy development to move in the right direction (to achieve them) is mandatory.

\section{FORMULATING STRATEGIES.}

The difference between strategies and action plans is mostly in detail. The basic concern of both is getting on with the mission. The strategy lays out the direction, and the program plan addresses detailed questions of resources and timing. Both deal with how we expect to achieve the objectives or ends desired. The strategy will be an enduring course of action (like a policy) that will be a guide for many years, and not just a single project or program that will be carried out in the next year or so. [Strategies will be specific enough, though, so that they suggest some programs or things to try.]

Here is a case study in strategy formulation. Early in a strategic planning effort by one DOE contractor, the objective had been set of "formally planning for the longer term future excellence of the site operations." Brainstorming of strategies (courses of action-direction) yielded the following alternatives/options:

- hire a consultant to tell us what to do and how

- appoint a committee of MBA types to do it

- appoint a small team of line managers to do it

- involve all the top line managers

- focus on a long term (10 yr.) future

- focus on both long and short term

- do it every two years from scratch

- do it on rolling-basis, with a new $10 \mathrm{yr}$. period each year

After debate and evaluation, the team consensus strategy was:

Involve the entire top management team, focus on the longer term future (10 yr.), and do it on a "rolling" basis.

The strategic direction this provides to the subsequent action planning is clearly helpful. The strategies above do not get into the details of implementation (who does what, when?), but they provide useful guidance and direction.

\section{EXAMPLES OF STRATEGIES.}

Some hypothetical examples of strategies may be of value in showing the general kind of direction that will be useful in driving program planning. Examples are the following:

- The National Energy Strategy is based on the principle of "sustainability," the capacity to continue production methods into the long-term future without depleting natural resources.

- Inform the public about the safety of existing plants and provide a public information program that will allow a clear comparison of the risks from alternatives.

- Inspire and motivate the entire DOE network to heightened excellence of 
performance by changing its culture to one of building pride in DOE's outstanding leaders/heroes and our accomplishments of the past, present, and future.

- Build stronger, more effective DOE management teams at the top level by involving key line managers in designing and planning together for a long term better future (strategic planning).

- Energy resource development, including energy conservation and energyefficiency improvements will be prioritized by weighing and balançing the trade-offs among reliability, risk, cost effectiveness, and environmental effects.
One potential pitfall in strategic planning is that of the planning team getting so enamored of their work that they generate many more strategies than the organization can tackle or devote resources to. Whether this is a problem will depend on the planning team and their "level" in the enterprise. It is most often a problem when sub-units are doing strategic planning.

The Secretarial Officers and their direct reports, as it has been suggested, have to be personally involved in the strategic planning steps up to this point. The next step of multiyear program planning will also require their accountability, but will require the major input and involvement of the rest of the organization.

\section{STRATEGIES - HELP MENU}

- In what new directions do we want to move to overcome the key barriers (issues)?

- Is it an enduring direction or just a one time action? It should be valid over the planning period.

- Is it motivational and challenging?

- Is it believable that we can move in that direction?

For more help see Reference 6, Chapter 8 pp. 163 to 183. 


\section{The Next Steps: Program Planning}

Using the objectives, issues, and strategies as input assumptions and guidance, the next step is to develop specific plans of action.

Action planning (multi-year program planning and subsequent budget preparations) is, of course, vital to the overall process. Peter Drucker says: ("The Practice of Management", Harper \& Row, 1974, pp. 128):

"The best plan is only a plan, that is, good intentions, unless it degenerates into work. The distinction that marks a plan capable of producing results is the commitment of key people to work on specific tasks. The test of a plan is whether management actually commits resources to actions which will produce results in the future. Unless such commitment is made, there are only promises and hopes, but no plan."

The multi-year program plans are the heart of the DOE system to carry out the strategies and to move toward our strategic objectives. The strategic plans should provide effective guidance and assumptions in the form of long-term direction (strategic objectives and strategies). From the multi-year program plans will flow, as previously, the more specific short-term operating budget plans that focus on today's problems and resources. But we and our various publics (stakeholders) should now be able to see that the near-term and mid-term projects and programs are focused on what DOE feels the best interests of the nation call for in the long haul. 


\section{How To "Do" Strategic Planning}

\section{PURPOSE AND ASSUMPTIONS.}

One of the many formats that might be used in strategic planning work is presented in this section. The purpose is to give those who have not been through this process an idea of the minimum time required and how it can be arranged effectively.

This format assumes a simple program and an ideal team, full team participation and attendance, no turnover of team members, good familiarity with the details of the mission , program and the various stakeholders by all team members, and maximum use of staff in gathering information. In the "real world" more time will likely be desired and needed.

\section{SAMPLE FORMAT.}

The first step is for the Secretarial Officer and his/her direct reports to meet in a preplanning session to agree on (see Planning for Strategic Planning Chapter) the following:

a. Number of strategic plans to be written for their organization (strategic planning units).

b. Planning period or horizon.

c. Who will be on the strategic planning team(s) and who will chair? (The Secretarial Officer will participate in the work of each team).

d. Needed agreements on staff involvement and liaison, calendar and off-site location preferences, etc.

e. Agreement of the group on using a facilitator to help with design and execution of process.

It will be helpful if the group drafts a mission statement at this pre-planning meeting. (See Chapter on the Mission Statement). If that is carefully crafted, it will be of much value in the discussions about whether the sub-businesses ought to have separate strategic plans. (Are the technologies, facilities, customers/clients, objectives, etc. quite distinct?)

For each strategic planning unit then, the format of a series of meetings to do strategic planning might consist of the following:

\section{A. An Initial Half-Day Session.}

(Away from the usual office and home conference rooms, but not necessarily off-site). The Planning Team and the Program Secretarial Officer, Facilitator if one, and a Staff Liaison person (who may well be one of the team).

\section{Agenda:}

a. Talk about strategic planning, what needs to be done and why and when.

b. Talk about the Steps and things this group needs to do in addition to minimal in Guidelines.

c. Talk about use of staff specialists and for which steps:

1.) Situation analysis including TrendsOpportunities/Threats etc.

2.) "Minutes" if any. The height of piles of paper is not a key performance indicator in strategic planning!

d. Talk about the mission for this organization and draft a statement.

e. Schedule all follow-on meetings.

\section{B. The Initial Off-Site.}

A two day session probably a month later at which the focus is on Situation Analysis, Vision and Setting Objectives. The Situation Analysis needs should be discussed at the earlier meeting and this session scheduled so staff has time to do their work.

\section{Agenda:}

a. Polish the mission statement and get consensus.

b. Situation Analysis-External Factors

Trends and Implications - opportunities and threats- presented by staff and then the group discusses which they wish to address.

c. Situation Analysis-Internal Factors

Past performance, present situation, strengths/weaknesses - presented by staff and group discusses importance to mission. 
d. Stakeholders-Who do we serve in what ways-what needs do they have which we need to address? Who should we be serving?

e. Start on Vision and Objectives.

\section{The Second Off-Site.}

A two day session (combined with the above session or following before too long) at which the focus is Vision and Objectives.

Agenda:

a. Envisioning the desired future, if needed, and brainstorming objectives.

b. Evaluating and Selecting Objectives.

c. Weighting (if desired) and Sharpening Objectives.

d. Start on Strategic Issues.

\section{The Third Off-Site.}

A two day session (combined with the above session or following it before too long) at which the focus is on Strategic Issues and Strategies.

Agenda:

a. Completion of issues identification.

b. Brainstorming of strategies or evaluation of staff proposal.

c. Selection of strategies.

d. Checking all elements of plan for compatibility completion.

e. Consensus on how plan will be packaged by the staff.

\section{E. The Closing Session.}

A half-day, on-site session about a month later to review the draft strategic plan. (Sent out in advance of session).

\section{Agenda:}

a. Revisit and refine strategies.

b. Review evaluations or feedback team has requested from "outsiders".

c. Review and comment on the written plan staff has prepared.

\section{FURTHER COMMENTS:}

1. If the "business" is very complex or if the Secretarial Officer wants inputs from component parts of the organization, the meetings will take more time.

2. It is desirable to preserve an atmosphere from meeting to meeting wherein team members can feel very easy about switching their positions and viewpoints and not be concerned about any constituencies. The model of our nation's 1787 Constitutional Convention delegates is a good one to follow, having confidential discussions until a consensus is reached on the final product. Then the plan and strategies need to be publicized and buy-in elicited.

3. Usually it is important for candor and openness of the team to keep the number of people in the off-site meetings small and to limit discussions to team members. Staff people should be asked to make their presentations and leave.

4. The off-site meetings obviously may be scheduled in various packages to suit the team; if they don't mind night sessions or weekends, it is possible to condense and do the job with only two offsites.

5. The emphasis on off-site meetings to do strategic planning arises from the difficulty of taking time out from the normal business day to sit back and think about what the long-term future might hold and directions one would like to see. It is very difficult to think about DOE's 30 year future (or that of any person/groups future) in the midst of a day when one is worrying about survival issues for this month! Well designed offsite meetings with a committed planning team of key managers can get it done. 


\section{How to Update Strategic Plans}

\section{PURPOSE AND ASSUMPTIONS}

The format suggested here for an annual review and update is centered around a two day offsite. It assumes that the Secretarial Officer and the same team that devised the plan is the group best qualified to review the approved plan of record. More than two days may be required if the program mission is complex (multiple) or if the planning team is larger than 8 or 9 . (See assumptions, page 19.)

The purposes of the offsite are:

a. To get the Secretarial Officer and top team members away from the daily crises to focus on the long-term.

b. To bring new team members up to speed on previous vision and direction setting.

c. To foster "performance improvement," upgrading all aspects of the previous planning.

d. To provide a useful framework for selfassessment of status and progress.

\section{SAMPLE FORMAT}

The plans for the review and update session should be made at a staff meeting about (at least) two months before the offsite. The questions to be answered are:

a. Time and place to hold the offsite.

b. Invitees to be members of the planning team. (See page 6)

c. Facilitator to help design and expedite the process.

d. Specialists needed to prepare briefings/ analyses for the team.

The latter briefings (d. above) are critically needed inputs for the team. They provide the new "situation analysis" and raise the points about changes that have occurred which may need to be reflected in the plan. Exactly what topics people should be asked to come talk about at the offsite will depend on the particular program or activity, but these topics might be considered: a. Changes in market demands or outlook

b. Changes in competition.

c. Changes in stakeholders and their expectations (including Congress, the public etc.)

d. Changes in Laws/Regulations

e. Changes in Technologies

f. Other (see page 9, "Situation Analysis)

In addition to the briefings above some internal staff person or preferably a member of the planning team should prepare a review of the validity of the planning assumptions used in the plan of record for presentation to the team.

Lastly, a staff person should be asked to prepare charts or analyses which show the status/progress on the strategic objectives and the key performance indicators.

The above presentations will enable the team to have a very productive review and will facilitate their strategic thinking, but these people will require time to prepare well, hence the suggestion that the specific topics and assignments be made well in advance of the offsite.

\section{THE OFFSITE-FIRST DAY}

Following the introductory remarks, the situation analysis inputs should make up the first part of the session. About 6 hours may be required, allowing perhaps a quarter to half hour for individual presentations and equal time for questions and team discussions. The focus must be on the longer-term implications/impacts.

Following the presentations, the team (by itself) should do their own self-assessment of the key factors, strengths, weaknesses, opportunities and threats to ascertain whether any significant change has occurred. (A proven, useful technique is described in Reference 6 , page 126). (2 hours)

That evening, a discussion of the mission and vision statements should address whether modifications to improve their clarity or to make them more inspiring could be made. If any 
signicant change in mission has occurred, then this offsite format should not be used and instead the mission change should be tackled first thing.

\section{THE OFFSITE-SECOND DAY}

The team should start with their selfassessment of progress made on the Key Performance Indicators and on the performance indicators for strategic objectives in the plan of record. They will need a well prepared briefing on this, and need to discuss whether any changes need to be made in milestones, targets, or indicators. ( 3 hours)

The key strategic issues should next be reviewed. The situation analysis presentations of the first day and reconsideration of the strategic objectives just completed should make this a productive discussion. (2 hours)

Following this, the team should talk about their strategies to determine whether any modification additions or deletions are warranted in view of their new look at the world the program or activity is living in and in view of the progress or lack of progress to date. (3 hours)

At the close of the session the team needs to decide whether any or just how much revision and repackaging is wanted, assign the job for revising, and set a 1/2 day or appropriate time several weeks hence to review and approve the new plan. It will also be necessary for the team to agree on whether changes justify or require approval by the Secretary or Deputy Secretary or Under Secretary. 


\section{Summary}

Strategic planning, someone said, is what you do to be sure the place you get is somewhere you want to be! A framework has been offered that should help Secretarial Officers and their key line managers hold some good discussions about the long-term future directions of their organizations. This will be of direct benefit to them in building a stronger consensus and understanding of that future direction, and in addition should be very productive in building a stronger management team. For these reasons, the process has usually been found to be more valuable than the product. In a report, even lengthy, one cannot communicate the good debates, exchanges, and struggles a group goes through in arriving at consensus on such vital issues as are at stake here. Careful attention to forming the planning team and to protecting the schedule and commitment each person makes to planning for the future in the midst of today's crises is vital to the success of the process.

In addition to these benefits for the planning team themselves, additional benefits will accrue from the sharing, review and discussion with the Secretary and other peer managers as well as with the organization reporting to the planning team. The strategic plan components should really help shape the program planning and execution work of the Field Offices and Sites. Strategic management, in which the longterm desired-future impacts day-to-day decisions, should become more natural and more effective-hopefully keeping this week's crises in better perspective.
The one certainty about our future is that our concepts and plans are bound to be wrong in detail. Changes will occur. We must resist the temptation to "cast our great objectives and strategies in concrete". Rather we should program our thinking to provide for periodic updates and changes or corrections in our directions and strategies.

The approach advocated in this document will appear to some people an overly simplistic or much too coarse treatment of strategic planning. It has been prepared with a view to helping our Secretarial Officers in strategic management of their very diverse activities. Some of them have had considerable experience and success with strategic planning and, for them, the minimal steps asked for herein will not be at all burdensome. For those who have not been personally engaged in such work before, it should be a rewarding experience.

It is again emphasized that some of the work of planning strategically, notably the data and analysis activities, may be delegated to other people. However, the "gut" work of mission definitions, objectives setting, issue formulation, and strategy development will require the personal involvement of Secretarial Officers and their direct reports, and that very personal involvement will lead DOE to make even greater contributions to the well-being of our nation and the world in the century ahead. 


\section{References And Sources Of More Information}

(In order of date of publication)

1. William R. King and David I. Cleland, STRATEGIC PLANNING AND POLICY, Van Nostrand Reinhold Co., New York 1978. (The use of their systems model of objectives and stakeholder approach has been very helpful).

2. George A. Steiner, STRATEGIC PLANNING: WHAT EVERY MANAGER MUST KNOW, Free Press, New York 1979.

3. Russell L. Ackoff, CREATING THE CORPORATE FUTURE, Wharton School of Business, University of Pennsylvania, John Wiley \& Sons, New York 1981.

4. George A. Steiner, John B. Miner, and Edmund R. Gray, MANAGEMENT POLICY AND STRATEGY, MacMillan, New York 1982.

5. Kenichi Ohmae, THE MIND OF THE STRATEGIST, Penguin Books, New York, NY., 1983.

6. John M. Bryson, STRATEGIC PLANNING FOR PUBLIC AND NON-PROFIT ORGANIZATIONS: $A$ Guide to Strengthening and Sustaining Organizational Achievement, Jossey-Bass, San Francisco, CA., April 1988.

7. William J. Wilcox, Jr., AN INTRODUCTION TO STRATEGIC PLANNING, Y-12 Plant Report YAD-599, Oak Ridge, Tenn. 1989. (The "Guidelines" are largely based on this work).

8. J. William Pfeiffer, Leonard D. Goodstein, and Timothy M. Nolan, SHAPING STRATEGIC PLANNING, Scott, Foresman, and Co., Glenview, III. 1989 (in association with University Associates, Inc., San Diego, Calif.)

9. THE NATIONAL ENERGY STRATEGY, Powerful Ideas tor America; 1 st Edition, 1991/1992, U.S. Department of Energy, Washington, D.C., Feb. 1991. 


\section{APPENDIX}

\section{FOREWORD TO THE EXAMPLE OF A STRATEGIC PLAN SUMMARY}

It will be useful to consider that the primary audiences and beneficiaries of the strategic planning effort are the following:

The Secretary, Deputy Secretary, and Under Secretary - in determining long-term strategic directions and policies for the Department and for making the final decisions on near-term resource allocations and priorities. In briefings with the Secretary on strategic plans, it will be very helpful for the Secretarial Officers to highlight the changes/differences between the situation, outlook, and assumptions that now exist and those which existed at the time of the last review. Focussing most of the discussions on the new or modified objectives, issues, and proposed strategies will be most productive.

Secretarial Officers - in clarifying missions, reviewing the present situation, identifying clients and customers, and highlighting long-term (beyond the next few years) objectives, issues, and strategies.

Administrators, Program Developers and Implementers - in providing guidance to those who are responsible for developing five year as well as shorter-term implementation plans and for seeing that the job gets done.

The purpose of strategic planning is to focus the attention of the leadership on what DOE might and ought to try to accomplish and how DOE might best serve the public interest in the long haul, and then to set the course to start to get there. This year's strategic plan is not to be thought of as an immutable creation, but rather as the best "shot" of today's leadership in view of today's realities. Change will occur: new circumstances, new threats, new opportunities, new crises, new people, new dreams. So this year's plan too will hopefully be reviewed and changed. But this year's program planning and resource allocations can more wisely and better be made if guided by our collective best judgment of where the organization wants to be in the long haul.

What follows next is a "dummy" plan summary, invented just for the purpose of illustrating the kinds of contents that might constitute the summary of a strategic plan for a DOE-type program. Any resemblance to actual situations is fortuitous, and the names, dates, and terms have obviously been chosen to help emphasize that the case is entirely fictitious. For this imaginary program a planning horizon of 40 years, to 2030, is used. It is hoped that this fancied summary of a number of days of intensive debate and study by the hypothetical planning team may be helpful in illustrating the kinds of summary outputs one might generate from the various elements of a strategic planning process. 


\section{THE MISSION STATEMENT FOR THE DOE ELECTRONUCLEAR PROGRAM}

The mission of the DOE electronuclear (EN) energy program is to understand the science and to develop, improve, and demonstrate the technology and, if the demonstrated economics and market needs then warrant, to facilitate the commercialization, introduction, and use of this new source of energy in the United States and by other peoples of the world, especially by developing nations. Experiments in our National Laboratories, who pioneered the basic research and development of this new energy source, convincingly show the promise of EN to provide large amounts of electricity to the public at lower overall costs and with fewer environmental impacts and at lower safety or health risks to the public than will those alternative energy sources which can supply the major electrical market needs.

DOE's role is to stimulate and nurture the development, testing, commercialization, and use of this technology by the public and private sector and by foreign nations, especially developing countries, with as little investment and cost to the Government as required to take advantage of the great promise of this new technology for serving the public interest.

\section{ELECTRONUCLEAR PROGRAM VISION STATEMENT -- 2030}

By 2030 we expect this new technology will have been fully developed and be well into commercial use, replacing fossil and nuclear plants that have reached the end of their licensed life as well as supplying new grid capacity where needed. EN technology should be generating power at total costs at least $20 \%$ (perhaps $50 \%$ ) less than competitive sources, thus meeting the Nation's needs for abundant, cheap, domestic origin, safe, and environmentally benign power and providing the bridge needed until fusion power becomes a reality on a large scale. There should be substantive reductions in oil imports, carbon dioxide and radwaste generation, etc. Utilization of EN by developing countries will be a major contribution to alleviation of hardships of their peoples. The DOE's role in this technology for the next decade will be as the prime mover and producer of the technology. In the decade 2010 to 2019 , assuming success, the utilities should take over in commercializing the technology, and DOE should be able to reduce its efforts sharply. By 2020 we should be able by 2020 to phase out all DOE work other than that required to give technical support to the Government's regulatory agencies. 


\section{Present Situation - 1998:}

The EN phenomenon, discovered by Parker at the U. of P. in 1992, was confirmed by researchers at three of the National Laboratories that same year. Research and development programs were undertaken at those Labs and at several Universities, and the potential for generating electricity soon became apparent. Because of the promise for producing electricity more economically (significantly less capital intensive) and with no hazardous or radioactive wastes and minimal environmental impacts, well-integrated major R\&D programs were mounted by DOE at Universities and four National Labs. These programs, now underway, are focused on the development of the component equipment, the process, and the facilities needed for substantive demonstration of EN power generation by 2005 to 2008. Planning for the demonstration is a cooperative venture involving representatives of utilities and regulatory groups as well as the scientists and engineers, under the overall direction of DOE. Independent economic evaluations are being sponsored by several impartial groups with complete access to all DOE information. Progress thus far has been very promising. Since our last plan review, the EPRI 1998 EN Outlook has been published and confirms the current DOE projections of potential \$/Mwday costs.

\section{The DOE Position:}

The DOE position today is that we have been the major funder (85\%), leader, and supporter of the technology thus far. The Department of Commerce has at our request initiated a special program to improve the metrics for EN monitoring. The Utilities, both public and investor-owned, have been extremely interested in watching progress and are funding independent studies of the potential for commercialization, but have not been willing to engage in any major cost sharing of the development work yet. At the last Annual Conference, COGEMA of France gave full reports on the work they initiated two years ago, and PNC of Japan announced successful but very small-scale pilot plant runs this year. The UKAEA continues to experience problems with the maintainability of the prototype equipment we supplied them for testing.

\section{Major Planning Assumptions:}

- The development of electronuclear technology will continue at its fast pace and not uncover problems that will block or be major obstacles to successful commercialization.

- Alternative sources in competition with EN (i.e. petroleum, coal, nuclear, fusion) will not achieve major breakthroughs in solving their environmental, availability, economic, or public acceptance problems.

- Market demands in the U.S. for electricity will continue to follow the forecasts of the past few years, sensitive to per capita and GNP indicators. Conservation programs will affect demand, but not more than that assumed in the official DOE forecasts.

- The indications found in the EN waste recycling trials in the QNL pilot plant runs that there will be no mixed or hazardous waste effluents will be substantiated in work with larger scale process equipment and heat fluxes.

- The trend toward increased regulatory involvement in planning for capacity increases by utilities will continue making it essential that we continue our efforts to involve them in following the early stages of EN development and planning.

- There will be continued pressure to reduce total DOE spending; thus, the needed EN program funding increases must continue to come from DOE reprogramming, requiring close working relationships and interchange of competitive position forecasts with alternative energy source offices (e.g., NE, CE, etc.). 


\section{SITUATION ANALYSIS -- KEY STAKEHOLDER CONSIDERATIONS}

Utilities = Major interest has been shown by both municipal, cooperative, and investor-owned utilities as the primary potential exploiters of EN technology. DOE's Annual Grand Junction Application Conferences have been heavily attended since their inception in 1993 and, by the evaluation of the utility reps attending, have been very successful in satisfying their needs. EPRI and EEI have each sponsored independent evaluations of the overall commercial \$/Mwday potential which generally confirm DOE projections. Since our last plan update, DOE has organized and invited their participation in an EN Advisory Board of American Utilities (elected by their associations and serving on a rotating basis) for the purpose of collaborating on planning strategies and cost sharing.

Universities $=$ Ten universities and three colleges have programs in aspects of EN science which complements the work in the National Labs. These programs are partially funded (40\%) by DOE. A continuing problem is the number of grant requests from other institutions which cannot be funded.

Regulatory Agencies and Oversight Bodies = Because of the major impact of regulatory bodies in the past on the competitive position of alternative energy sources such as nuclear, EN decided to invite representatives of the key regulatory groups to learn about EN early in its development years and to comment on planning and potential regulatory issues. This includes invitations to participate in the Annual Conferences and special briefings as desired. Members of Congress, their Staffs, and other key Executive and Legislative groups are specifically included.

Other Government Agencies $=$ There is a developing interest by NASA, the Dept. of State, and the Dept. of Transportation in EN technology. They have expressed interest in a MOU and formation of a joint administrative council. We continue to believe this to be premature, pending pilot scale demonstrations, and will hold annual briefings addressing their very different interests until that demo is accomplished.

Foreign Governments $=\quad$ Third World and developing nations have expressed interest in EN because of its advantages compared to nuclear, fusion, oil, coal, or natural gas power plants. They have not been invited to the Annual Conferences, but DOE has held one United Nations briefing co-sponsored with the State Department and is planning another in two years. Major R\&D programs are under way in France, UK, and Japan, and our Labs are watching their progress closely.

Other Sectors $=\quad$ Most interest to date has been in central station applications, but in the past year the number of inquiries to Headquarters and National Labs about potential applications in the automotive, transportation, and aerospace sectors make it desirable to mount a small effort at one of the Labs to assess potential applications in these areas.

Public $=$ The public acceptance problems with nuclear power appear to carry over to EN in the reaction of the media, despite all the good efforts of the scientists, engineers, and program administrators to set the record straight.

Internal Staff $=\quad$ Three National Labs have had major EN program efforts for five or more years. Smaller support-type efforts in specialty areas have been started in many other DOE sites and private sector shops. Cooperation in the early years was almost nonexistent, but the EN Management Council instituted in 1996 has proven fairly effective. Sharing of long-range goals and objectives has led to energetic competition, not toward different objectives, but to see who can reach the common objectives first and with least resource expenditure. 


\section{SITUATION ANALYSIS - KEY TRENDS}

\section{Research and Development Programs:}

The program has been underway only five years, and is still in the steep part of a normal learning s-curve. The progress made thus far is good. Projections suggest that total DOE spending will peak about 2008. (See chart below). DOE work should start decreasing about 2010 as commercialization either begins to take place or earlier if the potential does not appear to be realizable. Funding at the $\$ 300$ million per year level is required for the next two years, increasing to $\$ 350$ million for FY 2000 and 2001 period. The commercial small-scale demonstration project (scheduled to start design/construction in 2005 and start operation in 2015) is now scoped at $\$ 900$ million (1998 dollars). The primary technology questions (threats) remain in the area of reactor reliability, availability, and maintainability. The major program issue (threat) is the problem of fully funding the ongoing R\&D and the upcoming demonstration. A substantial political problem will be in the choice of location for the $\$ 900$ million demo, which decision will be needed in the 2002 time frame.

\section{Market Demands:}

DOE forecasts of demands and the contributions of the competing sources are shown below, jointly developed by the Headquarters offices. Growth is expected to somewhat lag behind GNP. (See chart below taken from the annual U.S.Energy Supply/Demand Forecasts prepared jointly by the concerned Program Offices).

Regulatory Pressures: Due to the effective efforts early in the decade, compliance issues have essentially been resolved, and institutional and technological structures and systems are in place to assure that R\&D and operations throughout DOE are responding to the current needs. The EN program is serving as a model for proactive leadership in working with regulatory groups in advance to anticipate and head off problems.
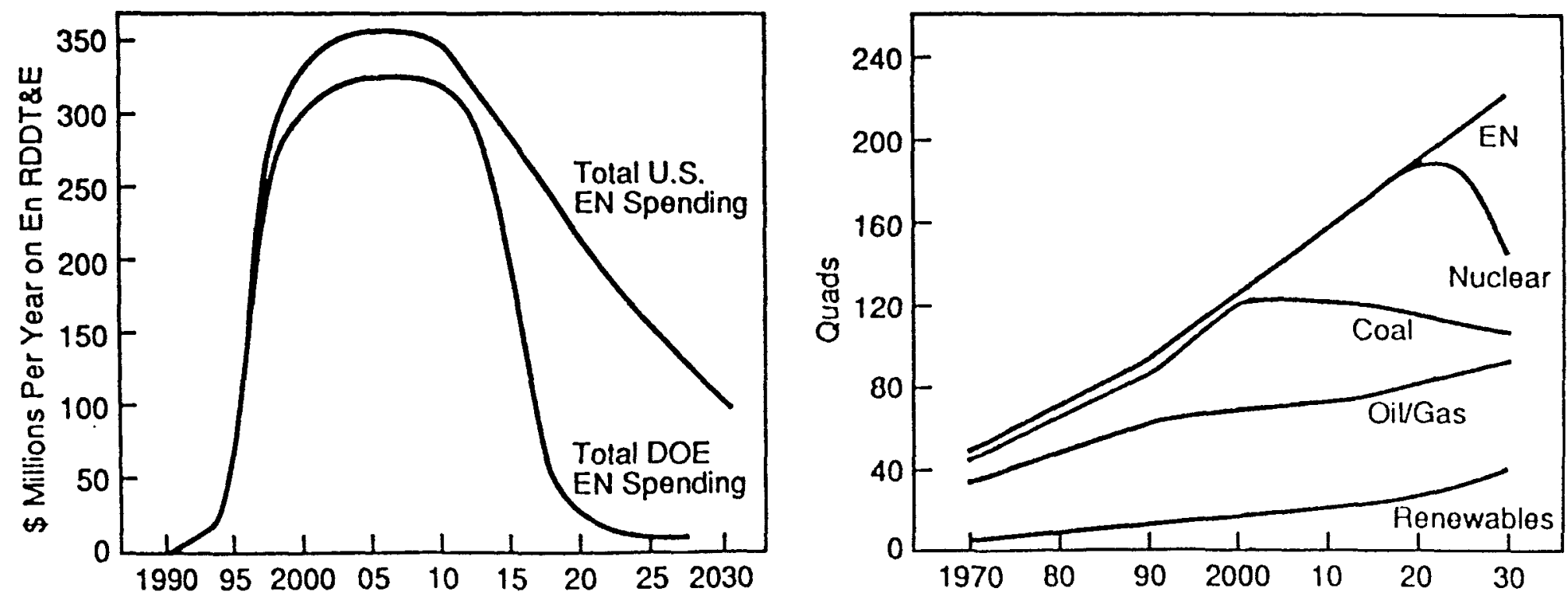
EN Technology:

- By 2005 the main elements of the basic science of the EN effect will be well understood.

- The technology will be demonstrated on a pilot scale by 2004 .

- The commercial-scale demo will be operational by 2012 , if earlier success justifies that step.

- Utilization of the technology by the U.S. and by foreign utilities or governments should be improving the quality of life and saving precious fossil fuels for better uses for many people by 2030 , and the EN share of the U.S. energy supply market will be $33 \%$.

\section{Compliance:}

- DOE will give proactive assistance in working with Federal, State, and Local regulatory bodies in establishing prudent regulations to assure the safety of people working in EN facilities and to protect the people and environment in the surrounding areas.

\section{Environment:}

- By 2003, DOE will be viewed nationally as an "environmental champion" - a leader in protecting and improving the environment around its EN and other active and formerly used sites.

Safety:

- DOE's EN program will be the leader in safety (as indicated by fully integrated injury and accident statistics) among the "big power" alternate sources: coal, fission, fusion, and petroleum.

Public:

- DOE will strive to achieve broad public acceptance for this power source. The goal is to have no public outcries or surprises and to develop an atmosphere of trust by the public that DOE's EN program is well serving the public's interests.

\section{Facilities:}

- Until 2015, DOE will provide and maintain a facility asset base at those National Labs involved in the EN program which will permit them to continue to support/solve problems arising in the use of EN energy until such time as a viable commercial industry can provide its own support, or until it is apparent EN will not become viable.

\section{Quality \& Excellence:}

- The EN Program will press for, stimulate, and reward improvements in EN technology, its applications, and use, which will reduce the unit costs of power, $\$ / \mathrm{Mwday}$ (DOE critical success indicator, see next page).

- A special objective for the near term is to reduce projected unit costs, $\$ / \mathrm{Mwday}$ (as currently projected by independent EPRI studies) by $20 \%$ below 1998 projections by the year 2010 (in year 1998 dollars).

(Note - The categories will, of course, vary with the Program under consideration, and can usually best be discerned after brainstorming and then boiling down a longer list of Objectives). 


\section{KEY PERFORMANCE INDICATORS}

The key, special indicators of progress and success of the EN program will be the following:

1. Share of the energy market supplied by EN relative to other supply sources, in percent of total U.S. quads for a given year.

2. Projected unit costs relative to other supply sources. The key performance indicator used by DOE will be the projected total costs (construction, operations, safeguards and security, environmental, waste, etc. -but not R\&D-, over the projected life of a commercial plant divided by the projected total electricity delivered to the bus, in year 1990 dollars per megawatt-day, \$/Mwday.

3. The safety, health, and environmental objectives performance indicator statistics need to reflect the integrated power supply business, i.e. the data should include statistics for all the needed inputs, supplies, waste processing, etc. for a given kind of power business, not just that of the central station.

[Note: The emphasis here is on the "Key" performance indicators. Each one of the strategic objectives will be measurable and those performance indicators should be utilized in program self-assessments if the data are meaningful for the time period under review. But there will usually be a few "Key" performance indicators, perhaps like number two above, which wrap together the impact of several objectives, which will be especially useful to the Secretarial Officer and planning team for evaluating the impact of their strategic thinking and actions, and these key performance indicators should be listed here.] 
- Sharply increased funding is needed to complete the pilot scale demo and prepare for the commercial demo, but substantial cost sharing will not be negotiable until promise of EN is more certain. Alternative sources (nuclear, fusion, coal) are competing for funds and have had much larger total investments over the years.

- How can the Department phase out and discontinue work on less promising/less needed programs of long standing that still have some merit as well as a cadre of specialist experts and fragile facilities -- in order to undertake new programs like EN that have a greater expected performance potential than competing technologies and greater longer-term benefit to the Nation?

- How can the Department work best (in these development years) with licensing/regulatory/oversight bodies to serve the Government's overall interest in assuring that safe and environmentally benign electricity is available for all its people?

- Limitations imposed by the Federal Power Act, Public Utility Holding Company Act, and State and local regulation unwisely inhibit development of supply options within the electric utility industry.

- How can DOE provide EN technology and equipment to Third World/developing countries and at the same time protect the interests of U.S. firms that wish to market that technology for profit?

- The technical problem of reuse of camerized source vessels must be solved over the next five years (before commercial demo design is ready) if waste treatment costs are to be acceptable. This is a potential fatal flaw in reaching target unit costs.

- Qualitative changes in our approach to the public and to the media are needed to overcome image problems of the past and to rebuild pride and confidence in the future of electronuclear power. 


\section{KEY STRATEGIES}

\section{Cost/Productivity:}

- Maximize value added for each dollar spent. Ask each EN group to set own specific productivity/quality improvement targets and liberally reward the best achievers, both organizations and leaders.

- Build a pride in achievement culture in EN which demands and honors excellence and celebrates important "wins."

\section{Service/Customers:}

- Work proactively to meet the needs and wants of utilities for information that will aid their planning for supplying electrical demands of the longer-term future.

- Make available or facilitate the process of granting low-cost loans to utilities needing to switch from high environmental impact technology to EN.

- Work with public utility commissions to modify rules so that utilities can include the cost of construction-in-progress in their rate base to encourage them to switch to EN or other less costly (overall) power technologies.

\section{Technology:}

- Strive for earliest possible identification of technical, operating, management, waste, off-gas, reliability, availability, maintainability, public relations, etc., problems in applying EN technology both in this country and in foreign developing nations. Capitalize on experience with existing power technologies by using their experts as "devil's advocates" panels to find "soft spots" in the developing EN technology applications.

\section{International:}

- Build a favorable climate for use of EN technology by developing nations to raise the quality of life for their people.

- Work toward international cooperation in $R \& D$ to share risks and costs of development.

\section{Human Resources:}

- Each year, strive to hire (both in Headquarters and field) a few of the best new graduates in science, engineering and management to help materialize the EN vision of 2030 and to upgrade (by replacement) the quality and competitive ability of the EN program staff.

- Honor top achievers who meet or exceed five year program objectives, and provide national recognition for the key EN program accomplishments.

\section{Facilities:}

- Use only existing DOE sites for new EN facilities to minimize capital and operating costs.

- Modernize existing site facilities for EN use only if and as they are required to meet EN strategic objectives.

Public Relations:

- Provide not only full disclosure of all substantative problems encountered with EN technology, but also provide the media and public information about the graded or relative risks involved so as to allow full understanding of their seriousness or importance. 